\title{
Response: Obesity Fact Sheet in Korea, 2018: Data Focusing on Waist Circumference and Obesity-Related Comorbidities (J Obes Metab Syndr 2019;28:236-45)
}

\author{
Ga Eun Nam', Won-Young Lee ${ }^{2, *}$ \\ ${ }^{1}$ Department of Family Medicine, Korea University Anam Hospital, Korea University College of Medicine, \\ Seoul; ${ }^{2}$ Division of Endocrinology and Metabolism, Department of Internal Medicine, Kangbuk Samsung \\ Hospital, Sungkyunkwan University School of Medicine, Seoul, Korea
}

\author{
Received July 24, 2020 \\ Reviewed August 11, 2020 \\ Accepted August 19, 2020 \\ ${ }^{*}$ Corresponding author \\ Won-Young Lee \\ https://orcid.org/0000-0002-1082-7592 \\ Division of Endocrinology and \\ Metabolism, Department of Internal \\ Medicine, Kangbuk Samsung Hospital, \\ Sungkyunkwan University School of \\ Medicine, 29 Saemunan-ro, Jongno-gu, \\ Seoul 03181, Korea \\ Tel: +82-2-2001-2579 \\ Fax: +82-2-2001-1588 \\ E-mail: drlwy@hanmail.net
}

Based on the 2018 Obesity Fact Sheet in Korea released by the Korean Society for the Study of Obesity, we reported incidence rates of chronic diseases including type 2 diabetes, hypertension, myocardial infarction, ischemic stroke, and cancers, and all-cause mortality rates according to waist circumference (WC) level. ${ }^{1}$ We analyzed the health check-up database between 2009 and 2016 provided by the Korean National Health Insurance System and calculated incidence rates and all-cause mortality rates standardized by age and sex using the 2010 census of the Korean population. We found that higher WC levels were positively associated with incidence rates of such comorbidities. However, regarding all-cause mortality rate, it was observed that the lowest WC level was associated with the highest all-cause mortality rate, and the highest WC level was associated with the second highest allcause mortality rate.

These results suggest that higher WC level is associated with higher all-cause mortality rates in subjects with abdominal obesity. This is in accordance with findings from the systematic review and meta-regression analysis of European studies indicating that WC has a J-shaped association with increased all-cause mortali- ty. ${ }^{2}$ However, among subjects without abdominal obesity in our study, a higher all-cause mortality rate was observed in those with lower WC level. Conversely, several studies have shown linear positive associations between WC size and mortality risk., ${ }^{3,4}$ Particularly in subjects without abdominal obesity or general obesity, lower WC size or body mass index (BMI) may attribute to various causes. Compared with higher WC size or BMI, people with lower WC size or BMI may be more likely to be current smokers, to have comorbidities, or to be in poor nutritional status related to decreased WC size or loss of body weight and these conditions related to unintentional weight loss may increase mortality risk. ${ }^{5,6}$ Moreover, there may exist various confounding factors that are potentially associated with mortality risk. However, we did not consider these confounding factors besides standardization for age and sex, thus our analysis cannot confirm the association between WC size and the risk of all-cause mortality as well as the development of comorbidities.

Meanwhile, the U-shaped association between WC level and all-cause mortality rate in our study can be partly explained by the paradoxical association between obesity and mortality risk. 
Although the majority of studies on this issue have measured obesity using BMI, studies using less-frequent measures of body composition including WC and waist to hip ratio have also suggested the obesity paradox. ${ }^{7,8}$ However, the obesity paradox has been predominantly reported among elderly individuals and patients with comorbidities. ${ }^{9}$ Furthermore, WC may have a differential relationship with mortality according to age, sex, and BMI. ${ }^{10}$

In this regard, future studies that consider potential confounders related to change in WC and mortality risk are needed to examine better the association between WC and the risk of mortality. Subgroup analyses by age, BMI, comorbidities, and specific causes of mortality should be also considered to reveal the association between WC and mortality risk.

\section{CONFLICTS OF INTEREST}

The authors declare no conflict of interest.

\section{AUTHOR CONTRIBUTIONS}

Study concept and design: all authors; drafting of the manuscript: all authors; critical revision of the manuscript: all authors; and study supervision: WYL.

\section{REFERENCES}

1. Nam GE, Kim YH, Han K, Jung JH, Park YG, Lee KW, et al. Obesity fact sheet in Korea, 2018: data focusing on waist circumference and obesity-related comorbidities. J Obes Metab Syndr 2019;28:236-45.

2. Carmienke S, Freitag MH, Pischon T, Schlattmann P, Fankhaenel T, Goebel H, et al. General and abdominal obesity param- eters and their combination in relation to mortality: a systematic review and meta-regression analysis. Eur J Clin Nutr 2013; 67:573-85.

3. Jacobs EJ, Newton CC, Wang Y, Patel AV, McCullough ML, Campbell PT, et al. Waist circumference and all-cause mortality in a large US cohort. Arch Intern Med 2010;170:1293-301.

4. Zhang C, Rexrode KM, van Dam RM, Li TY, Hu FB. Abdominal obesity and the risk of all-cause, cardiovascular, and cancer mortality: sixteen years of follow-up in US women. Circulation 2008;117:1658-67.

5. De Stefani FD, Pietraroia PS, Fernandes-Silva MM, Faria-Neto J, Baena CP. Observational evidence for unintentional weight loss in all-cause mortality and major cardiovascular events: a systematic review and meta-analysis. Sci Rep 2018;8:15447.

6. Donini LM, Pinto A, Giusti AM, Lenzi A, Poggiogalle E. Obesity or BMI paradox? Beneath the tip of the iceberg. Front Nutr 2020;7:53.

7. Horwich TB, Fonarow GC, Clark AL. Obesity and the obesity paradox in heart failure. Prog Cardiovasc Dis 2018;61:151-6.

8. Sandhu RK, Ezekowitz J, Andersson U, Alexander JH, Granger CB, Halvorsen S, et al. The 'obesity paradox' in atrial fibrillation: observations from the ARISTOTLE (Apixaban for Reduction in Stroke and Other Thromboembolic Events in Atrial Fibrillation) trial. Eur Heart J 2016;37:2869-78.

9. Nam GE, Park HS. Perspective on diagnostic criteria for obesity and abdominal obesity in Korean adults. J Obes Metab Syndr 2018;27:134-42.

10. Cho GJ, Yoo HJ, Hwang SY, Choi J, Lee KM, Choi KM, et al. Differential relationship between waist circumference and mortality according to age, sex, and body mass index in Korean with age of 30-90 years; a nationwide health insurance database study. BMC Med 2018;16:131. 